\title{
Impact of singlehood during pregnancy on dietary intake and birth outcomes- a study in the Norwegian Mother and Child Cohort Study
}

Jorunn Farbu*, Margaretha Haugen, Helle Margrete Meltzer and Anne Lise Brantsæter

\begin{abstract}
Background: Little attention has been given to the impact of singlehood during pregnancy. The aim of this study was to examine the impact of marital status on diet during pregnancy and pregnancy outcome.

Methods: The study population comprised 62,773 women participating in the Norwegian Mother and Child Cohort Study. Marital status was categorised into singles living alone, singles living with parents and married/cohabiting (reference group). Participants answered a general health questionnaire in gestational week 15-17 and a food frequency questionnaire in gestational week 22 . We used nonparametric tests to compare dietary intakes by marital status, and multiple logistic regression to estimate odds ratios (OR) and $95 \%$ confidence intervals (Cl) for infants being small for gestational age (SGA), large for gestational age (LGA), and preterm delivery (defined as delivery before gestational week 37).

Results: Single women living with parents had lower intakes of fruits and vegetables, higher intake of total energy, higher proportion of energy from added sugar, and lower intake of fibre than the reference group. Singles living alone also had a higher intake of added sugar. In both of the single groups, daily smoking was more prevalent than in women living with a partner. In analyses adjusted for maternal age, pre-pregnancy BMI, energy intake, energy contributed by protein, education, income, parity and nausea, single women living alone had increased risk of SGA with $\mathrm{OR}=1.27(95 \% \mathrm{Cl}: 1.05,1.55)$. When smoking was included among the confounding variables, the association was no longer significant. Likewise, singles living alone had increased risk of preterm delivery, with $\mathrm{OR}=1.32$ (95\% Cl: $1.01,1.72)$ in a partly adjusted model, but the association did not remain significant in a model fully adjusted for confounding variables.
\end{abstract}

Conclusions: Single mothers had lower dietary quality and included more smokers than women who lived with a partner. Single mothers living alone had higher prevalence of SGA and preterm delivery, but the associations with adverse pregnancy outcomes were confounded by other variables. This study shows that single mothers should be given special attention during antenatal care and counselling.

Keywords: Marital status, Singlehood, The Norwegian Mother and Child Cohort Study, MoBa, Food frequency questionnaire

\footnotetext{
* Correspondence: jorunn.farbu@gmail.com

Division of Environmental Medicine, Norwegian Institute of Public Health,

P.O. Box 4404, Nydalen NO-0403, Oslo, Norway
} 


\section{Background}

There have been major changes in household composition the last decades, with increased proportion of children being born to single mothers. According to Statistics Norway, $13 \%$ of all children were born to single mothers in 2013, as compared to $9 \%$ in 1994 [1]. Marital status has been associated with adverse health behaviour, including poorer eating habits, with higher prevalence of cardio-vascular disease, type II diabetes, obesity and mental illness in single households than in families [2-4]. A systematic review and meta-analysis of twenty-one studies, published in 2011 concluded that single women had increased risk of adverse pregnancy outcomes, including preterm delivery, low birth weight and small for gestational age infants [5].

Foetal development is characterized by rapid growth, sensitive to quality and quantity of nutrients consumed during pregnancy [6] and maternal diet may impact the long-term health of both mothers and children [7-10]. Birth weight is a marker of foetal growth and a predictor of infant survival and health status. Birth weight depends on gestational length and the outcomes 'small for gestational age' (SGA) and 'large for gestational age (LGA)' are used to identify high risk infants. Maternal intake of micronutrients [11,12], macronutrients [13], as well as food intakes [14-17] has been associated with pregnancy outcomes including SGA, LGA and gestational length.

Studies have shown that pregnant women often fail to meet their respective countries' dietary recommendations [18-20], but few have reported dietary quality or food intake in pregnant single women [21,22]. To the best of our knowledge, no previous studies have examined the associations between marital status and pregnancy outcomes taking maternal diet into account. The objective of the present study was therefore to examine the impact of marital status on diet during pregnancy and the pregnancy outcomes SGA, LGA and preterm delivery.

\section{Methods}

\section{Population and study design}

The Norwegian Mother and Child Cohort Study (MoBa) is a prospective population-based pregnancy cohort study conducted by the Norwegian Institute of Public Health. Participants were recruited from all over Norway from 1999-2008. The women consented to participation in $40.6 \%$ of the pregnancies. The cohort now includes 114,500 children, 95,200 mothers and 75,200 fathers [23]. The study aims to follow the children up to 14 years of age through questionnaires, and later in life through Norway's many health registries. Women were recruited to the study through a postal invitation in connection with their first routine ultrasound control at week 17-18 of pregnancy. Data were collected through comprehensive questionnaires and blood and urine samples to provide researchers with a wide range of data for future hypothesis testing. Nearly all participants were of Caucasian ethnicity. The data from MoBa were linked to the Medical Birth Registry of Norway (MBRN), in which all births and stillbirths have been registered since 1967 [24]. Informed consent was contained from all participants before study entry. The study was approved by the Regional Committee for Ethics in Medical Research and the Data Inspectorate in Norway.

The current study uses the quality-assured data files released for research in 2009 (version 4). Data collected for this study were collected from questionnaire 1 (Q1) and questionnaire $2(\mathrm{Q} 2)$. Q1, received in pregnancy weeks 13-15, comprised socio-demographic information and general health, while Q2 is a semi quantitative food frequency questionnaire sent to the participants around week 17-22 of pregnancy.

The participants in the present study were recruited between 2002 and 2007. In total, 62,773 women were eligible to participate in the current study. The women included were those who participated for the first time and had answered both Q1 and Q2. Other inclusion criteria were: having reported a valid energy intake [25] and having reported the same marital status in the MBRN register at the time of delivery as in the first MoBa questionnaire. A flow diagram for inclusion of participants is presented in Figure 1. For studying the association between marital status and the birth outcomes SGA, LGA and preterm delivery, we excluded women with multiple pregnancies (twins/triplets, $\mathrm{n}=1232$ ) and those with missing data on infant birth weight or gestational length $(n=595)$, resulting in 60,946 women. Women with missing information $(n=1007)$ or contradictory information ( $\mathrm{n}=373$ ) on marital status (Figure 1) were categorized as a "missing marital information" group and included in a sensitivity analysis.

\section{Definition of marital status}

The participants were divided into singles living alone (SA), singles living with parents (SP) and married/cohabiting $(\mathrm{M} / \mathrm{C})$. The single category was divided in two due to the differences in age and living conditions between these two sub-groups.

\section{Dietary information}

The MoBa FFQ (downloadable from www.fhi.no/dokumenter/ 011fbd699d.pdf) is a semi-quantitative questionnaire that asked about the intake of 255 food items and was specifically designed to capture dietary habits and intake of dietary supplements during the first 4-5 months of pregnancy [25]. The questionnaires were optically read. Frequencies were converted into food intakes and nutrient calculations were performed with the use of FoodCalc [26] and the Norwegian food composition table. A validation study 


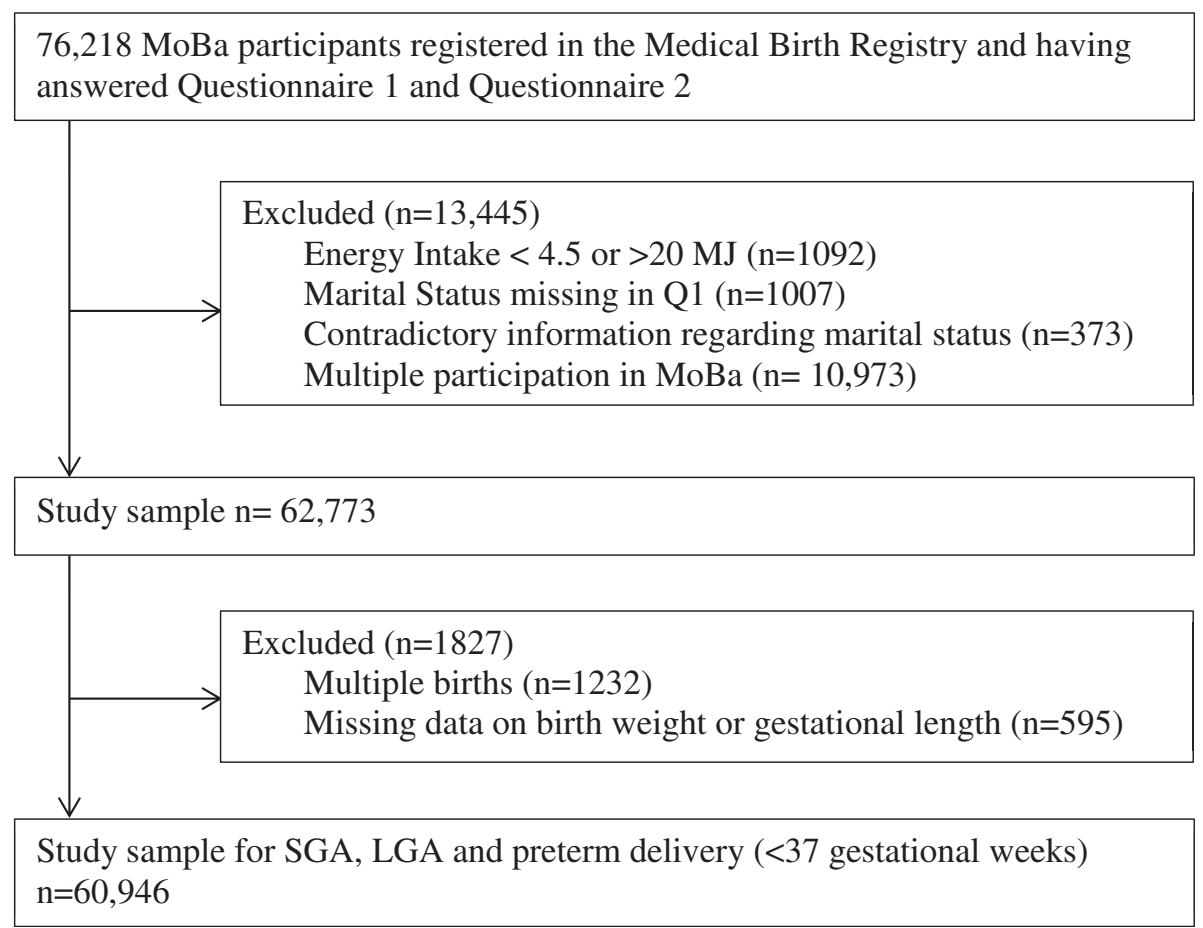

Figure 1 Flow diagram for inclusion of participants.

showed that compared to a dietary reference method and biological markers of intake, the FFQ produces a realistic estimate of the habitual intake and is a valid tool for ranking pregnant women according to high and low intakes of energy, nutrients and food [27-29].

\section{Pregnancy outcomes}

The pregnancy outcomes included in the present study were a) small for gestational age (SGA), b) large for gestational age (LGA) and c) preterm delivery. The variables SGA and LGA were calculated from the 10th percentile and 90th percentile of birth weight within gestational week for nulliparous and multiparous pregnancies respectively. Preterm delivery was defined as pregnancies with gestational length shorter than 37 complete weeks. The information related to gestational length and infant birth weight was retrieved from the MBRN. Gestational length was calculated from ultrasound measurements at week 17-18, with the exception of a few women with missing ultrasound information. For these women, gestational length was calculated from the date of their last menstruation.

\section{Other variables}

Maternal age at delivery reported in MBRN was used as a continuous variable with exception of descriptive statistics, for which it was divided into five categories $(<20,20-24$, $25-29,30-34$, and $\geq 35$ ). BMI was calculated from selfreported height and weight before the pregnancy reported in Q1 and categorized according to the World Health Organization classification as normal $\left(18.5-24.9 \mathrm{~kg} / \mathrm{m}^{2}\right)$, underweight $\left(<18.5 \mathrm{~kg} / \mathrm{m}^{2}\right)$, overweight $\left(25.0-29.9 \mathrm{~kg} / \mathrm{m}^{2}\right)$ and obese $\left(\geq 30.0 \mathrm{~kg} / \mathrm{m}^{2}\right)$. Education was divided into four categories ( $<12$ years, 12 years, $13-16$ years and $\geq 17$ years). Smoking habits during the first part of pregnancy were reported in Q1. We categorised smoking into three groups: daily smokers, occasional smokers and non-smokers. Q1 included a short version of the Hopkins Symptom Checklist. We included a dichotomous variable denoting whether women had experienced feeling depressed or sad for a continuous period of more than two weeks during the first part of pregnancy [30]. The variable was used as an indicator of mental wellbeing.

\section{Statistical methods}

Initially data were analysed for missing values and normality of continuous data. For the maternal demographics, chi-square was used for nominal data. Food and nutrient intakes are presented as medians, 5 and 95 percentiles (P5, P95). For all continuous variables, the Kruskal-Wallis test was chosen when comparing three groups, and Mann-Whitney-U test was chosen when comparing two groups due to the differences in the group sizes. Logistic regression was used to estimate odds ratios (OR) and 95\% confidence intervals (CI). Each of the pregnancy outcomes SGA, LGA and preterm delivery were modelled as dependent variables and adjusted for dietary variables (total energy and nutrient intakes) and potential 
confounding variables (maternal characteristics presented in Table 1). Dietary intakes and confounding variables were included in the models if they were associated both with marital status and the outcome with $p<0.100$. The following variables were included in the final models: total energy intake, energy contributed by protein, maternal pre-pregnancy $\mathrm{BMI}$, education, income, parity, age at delivery, nausea at the time of filling in the FFQ and smoking during pregnancy. All analyses were performed using SPSS version 17. All p-values were two sided and values $<0.05$ were considered significant.

\section{Results}

Of the 62,773 women in this study, 61,646 (98.2\%) were married/cohabiting, $218(0.3 \%)$ were single living with their parents, and 909 (1.5\%) were single living alone.

Maternal characteristics differed substantial by marital status (Table 1). The single groups were younger, and had lower education and income than the married/cohabiting group. In particular, the prevalence of smoking was higher in the single groups. Singles also reported higher prevalence of feeling depressed or sad for a prolonged time. There were major differences also between the two single groups, with singles living alone representing a more heterogeneous group than singles living with parents (Table 1).

Food intakes differed substantial by marital status (Table 2). Compared to married/cohabiting women, singles living alone had higher intake of full fat milk and lower intake of meat, while singles living with parents had lower intakes of vegetables and whole grain products, and higher intakes of full fat milk and sugared sweetened drinks. Analyses of selected nutrient intakes by marital status reflected the differences in food intake (Table 3). Both single groups had higher energy intake, particularly energy contributed by added sugar, but also less energy contributed by protein. The singles living alone had higher intakes of saturated fat and both single groups had lower intake of dietary fibre than the married/cohabiting group, whereas the singles living with parents had lower intake of folate both from food and supplements.

Analysis of associations between marital status and pregnancy outcome (Table 4) showed that singles living alone had significantly higher risk of SGA and preterm delivery than the married/cohabiting women after adjusting for the nutrition related variables (maternal BMI, total energy intake and energy contributed by protein, Table 4 , Model 1). For SGA, the association remained significant after additional adjustment for maternal education, income, parity and age of delivery (OR: 1.27, 95\% CI: 1.05, 1.55) (Table 4, Model 2). However, after adjusting also for maternal smoking the association did no longer remain significant (Table 4, Model 3). Likewise, singles living alone had increased risk of preterm delivery in the model adjusted for nutrition related variables, with $\mathrm{OR}=1.32$
(95\% CI: 1.01, 1.72) (Table 4, Model 1), but the association did not remain significant when additional confounding variables were included (Table 4, Models 2 and 3 ).

In a sensitivity analysis we included women with missing or inconsistent information on marital status (n 1380) in a 'missing marital information group'. Comparison of age, education, smoking status, parity and the prevalence of pregnancy outcomes in this group and the three marital groups in the study, showed that the missing group comprised women from all three groups. Compared to the reference group (married/cohabiting), the missing group was not associated with any pregnancy outcomes (data not shown). Furthermore, including the missing group in the analysis of marital status versus pregnancy outcomes did not change the associations reported in Table 4.

\section{Discussion}

The main finding of the present study was the differences in dietary quality with regard to marital status. Singles living with parents and singles living alone had lower nutrient dense diets than women who were married/cohabiting. Singles living alone had higher risk of SGA and preterm delivery than women living with a partner. However, the associations were confounded by other socioeconomic and lifestyle variables, in particular maternal education and smoking.

The observed difference in dietary quality between pregnant single women and those living with a partner (Tables 2 and 3 ) is in accordance with previous studies linking diet to marital status $[21,22]$. Northstone et al. examined associations between dietary patterns in pregnancy and sociodemographic and lifestyle factors in a British cohort, and reported lower adherence to a 'health conscious' and higher adherence to a 'processed' dietary pattern in women who were single than in non-singles [21]. Similar associations were seen for education. Another recent study using data from MoBa examined whether loneliness, marital status, and other factors were associated with consumption of sodas and juices. Their results showed that being married or cohabiting was associated with a lower intake of sugarcontaining beverages [22].

The difference between the two single groups observed in our study may partly be explained by age, education and socioeconomic status. Adolescents more often have energy dense and nutrient poor diets [31,32]. In non-pregnant populations it has been shown that children's eating patterns mirror what is available at home, and that parental education, particularly maternal education, is closely associated with adolescents' dietary habits $[4,33,34]$.

Marital status has been associated with health, health related behaviours and birth outcomes [2,3,5]. A systematic review and meta-analysis of 21 cohort studies in developed countries concluded that compared to women who were married, single women had increased risk of 
Table 1 Maternal characteristics by marital status $(n=62,773)$

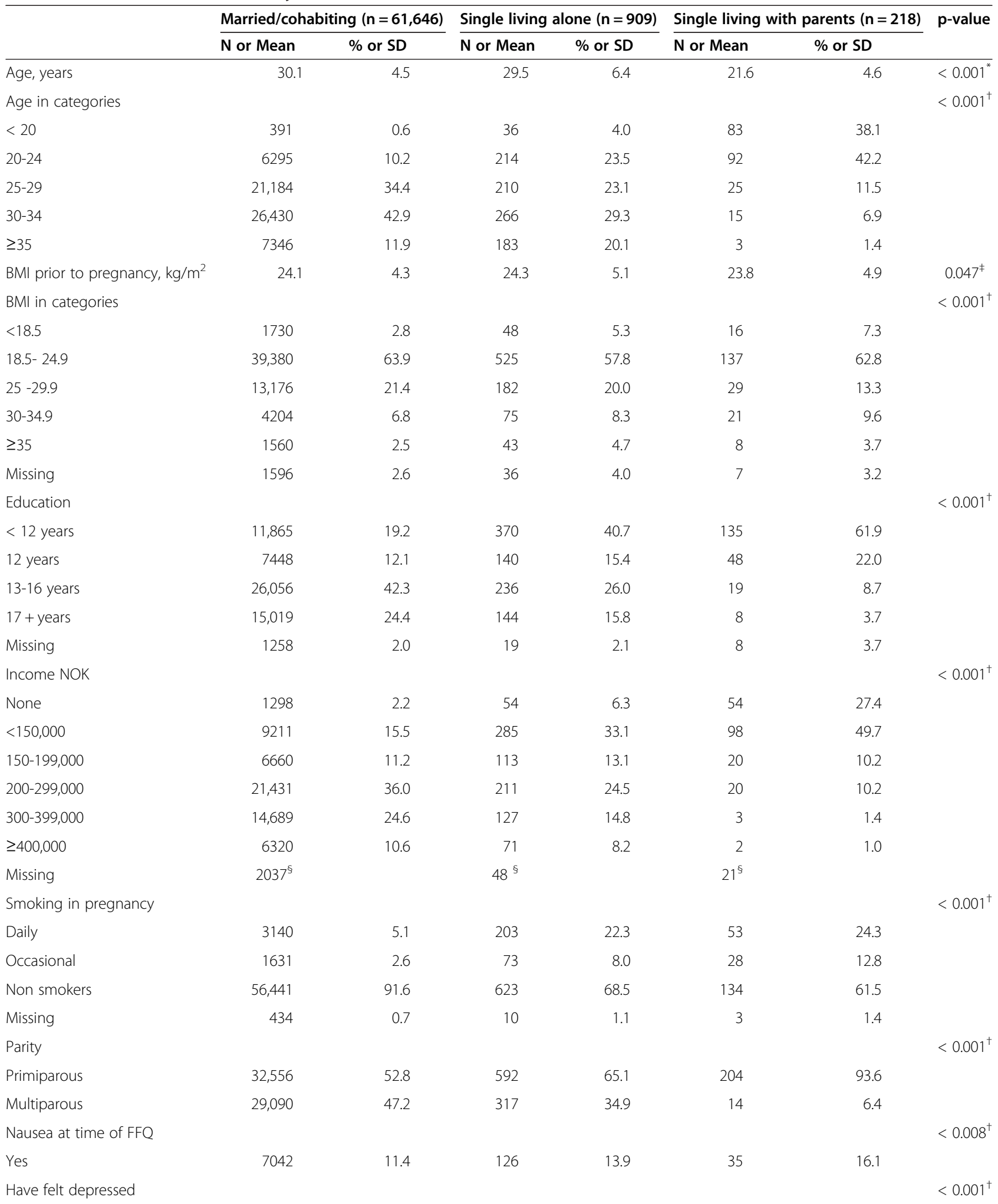


Table 1 Maternal characteristics by marital status $(n=62,773)$ (Continued)

\begin{tabular}{lrrrrrrr}
\hline Yes & 30,147 & 48.9 & 609 & 67.0 & 128 & 58.7 \\
Missing & 655 & 1.1 & 16 & 1.8 & 6 & 2.8 & \\
\hline
\end{tabular}

SD, Standard deviation.

*One-way Anova with post hoc tests.

${ }^{+} X^{2}$ test.

${ }^{\ddagger}$ Kruskal-Wallis test.

${ }^{\S}$ Not included in the percent distribution.

preterm delivery, low birth weight and SGA [5]. However, there was large heterogeneity among the studies, and only some studies included adjustment for socioeconomic variables.

In the current study, associations between marital status and pregnancy outcomes were clearly modified by confounding variables, particularly smoking and education (Table 4). Similar to our study, a study not included in the review, with 304 unmarried and the same number of matched controls, did not find any associations between marital status and risk of preterm delivery or SGA [35]. It could be questioned whether marital status is merely a marker of socioeconomic status. Although
Norway is believed to be an egalitarian society, several studies have shown that socioeconomic variables, particularly maternal education and household income, are associated with health behaviour and pregnancy outcomes [34,36-38].

Singles living alone represented a more diverse group in terms of age, education and economy than single women living with parents. Older and more educated single mothers might have a less stress-related burden in their pregnancies, and in the highest income category $(\geq 400,000$ NOK) there were almost as many single women living alone (8.2\%) as married/cohabiting (10.6\%). The percentage of mothers aged 35 years or more were highest in the

Table 2 Food intakes (g/day) by marital status $(n=62,773)$

\begin{tabular}{|c|c|c|c|c|c|c|c|c|c|c|c|c|}
\hline & \multicolumn{3}{|c|}{$\begin{array}{l}\text { Married/cohabiting } \\
(\mathrm{M} / \mathrm{C}) \mathrm{n}=61,646\end{array}$} & \multicolumn{3}{|c|}{$\begin{array}{l}\text { Singles living alone } \\
\text { (SA) } n=909\end{array}$} & \multirow{2}{*}{$\begin{array}{l}\text { SA vs } M / C \text { * } \\
\text { p-value }\end{array}$} & \multicolumn{3}{|c|}{$\begin{array}{l}\text { Singles living with } \\
\text { parents (SP) } n=218\end{array}$} & \multirow{2}{*}{$\begin{array}{l}\text { SP vs } M / C^{*} \\
\text { p-value }\end{array}$} & \multirow{2}{*}{$\begin{array}{l}\text { SA vs SP* } \\
\text { p-value }\end{array}$} \\
\hline & Median & P5 & P95 & Median & P5 & P95 & & Median & P5 & P95 & & \\
\hline Dairy all & 420 & 50 & 1160 & 410 & 50 & 1330 & 0.222 & 460 & 50 & 1740 & 0.012 & 0.117 \\
\hline Full fat milk & 2 & 0 & 200 & 13 & 0 & 400 & $<0.001$ & 31 & 0 & 820 & $<0.001$ & $<0.001$ \\
\hline Low fat milk & 250 & 0 & 880 & 210 & 0 & 1200 & 0.024 & 200 & 0 & 1200 & 0.590 & 0.714 \\
\hline Cheese & 17 & 2 & 61 & 15 & 1 & 65 & 0.001 & 10 & 1 & 56 & $<0.001$ & $<0.001$ \\
\hline White bread & 97 & 0 & 290 & 86 & 0 & 320 & 0.957 & 120 & 1 & 360 & 0.001 & 0.002 \\
\hline Dark bread & 45 & 0 & 270 & 45 & 0 & 270 & 0.295 & 6 & 0 & 270 & $<0.001$ & $<0.001$ \\
\hline Cereals, porridge & 11 & 0 & 110 & 10 & 0 & 115 & 0.017 & 7 & 0 & 90 & $<0.001$ & 0.022 \\
\hline Fruit & 221 & 50 & 620 & 203 & 34 & 680 & 0.110 & 186 & 0 & 90 & 0.006 & 0.091 \\
\hline Vegetables & 135 & 43 & 340 & 127 & 33 & 370 & 0.065 & 100 & 15 & 330 & $<0.001$ & $<0.001$ \\
\hline Meat all & 99 & 55 & 148 & 93 & 44 & 155 & $<0.001$ & 96 & 47 & 160 & 0.285 & 0.179 \\
\hline Poultry & 17 & 0 & 47 & 15 & 0 & 48 & $<0.001$ & 12 & 0 & 46 & $<0.001$ & 0.030 \\
\hline Seafood all & 34 & 6 & 76 & 35 & 0 & 83 & 0.397 & 30 & 0 & 81 & 0.232 & 0.184 \\
\hline Fatty fish & 8 & 0 & 38 & 8 & 0 & 40 & 0.291 & 6 & 0 & 32 & $<0.001$ & 0.002 \\
\hline Pizza, taco & 18 & 13 & 25 & 18 & 11 & 26 & 0.006 & 20 & 13 & 28 & 0.047 & 0.007 \\
\hline Potatoes, boiled or mashed & 38 & 1 & 100 & 29 & 4 & 120 & $<0.001$ & 56 & 10 & 130 & $<0.001$ & $<0.001$ \\
\hline French fries, fried potatoes & 10 & 0 & 17 & 10 & 0 & 17 & 0.719 & 10 & 0 & 17 & $<0.001$ & $<0.001$ \\
\hline Sugar sweetened drinks & 55 & 0 & 610 & 67 & 0 & 1020 & 0.081 & 140 & 0 & 1500 & $<0.001$ & $<0.001$ \\
\hline Coffee & 4 & 0 & 107 & 5 & 5 & 150 & 0.034 & 0 & 0 & 16 & $<0.001$ & $<0.001$ \\
\hline Cakes & 6 & 0 & 22 & 6 & 0 & 27 & $<0.001$ & 6 & 0 & 29 & 0.003 & 0.587 \\
\hline Sweets & 17 & 1 & 80 & 16 & 0 & 89 & 0.028 & 15 & 0 & 105 & 0.305 & 0.980 \\
\hline Salty snacks & 12 & 2 & 36 & 10 & 0 & 45 & 0.002 & 13 & 0 & 63 & 0.133 & 0.014 \\
\hline Olive oil & 0.4 & 0 & 3.0 & 0.2 & 0 & 2.1 & $<0.001$ & 0.1 & 0 & 2.1 & $<0.001$ & 0.001 \\
\hline
\end{tabular}

*Mann-Whitney $\mathrm{U}$ test, $\mathrm{P5}, 5^{\text {th }}$ percentile; $\mathrm{P95}, 95^{\text {th }}$ percentile. 
Table 3 Selected nutrient intakes by marital status

\begin{tabular}{|c|c|c|c|c|c|c|c|c|c|c|c|c|}
\hline & \multicolumn{3}{|c|}{$\begin{array}{l}\text { Married/cohabiting } \\
(\mathrm{M} / \mathrm{C}) \mathrm{n}=61,646\end{array}$} & \multicolumn{3}{|c|}{$\begin{array}{l}\text { Singles living alone } \\
\text { (SA) } n=909\end{array}$} & \multirow{2}{*}{$\begin{array}{l}\text { SA vs } M / C^{*} \\
\text { p-value }\end{array}$} & \multicolumn{3}{|c|}{$\begin{array}{l}\text { Singles living with } \\
\text { parents }(S P) n=218\end{array}$} & \multirow{2}{*}{$\begin{array}{l}\text { SP vs } M / C^{*} \\
\text { p-value }\end{array}$} & \multirow{2}{*}{$\begin{array}{l}\text { SA vs SP } \\
\text { p-value }\end{array}$} \\
\hline & Median & P5 & P95 & Median & P5 & P95 & & Median & P5 & P95 & & \\
\hline Energy, MJ & 9.4 & 6.1 & 14.6 & 9.7 & 5.8 & 15.9 & 0.002 & 10.1 & 5.6 & 16.6 & $<0.001$ & 0.081 \\
\hline Protein energy $\%$ & 15.4 & 12.1 & 19.0 & 15.1 & 11.3 & 19.1 & $<0.001$ & 14.7 & 10.9 & 19.3 & $<0.001$ & 0.002 \\
\hline Fat energy \% & 30.3 & 23.2 & 37.9 & 30.5 & 22.9 & 39.7 & 0.147 & 31.0 & 21.5 & 37.5 & 0.987 & 0.477 \\
\hline Carbohydrate energy \% & 53.8 & 46.3 & 61.8 & 53.9 & 44.5 & 63.1 & 0.707 & 54.1 & 46.8 & 64.0 & 0.143 & 0.145 \\
\hline Added sugar energy $\%$ & 9.8 & 4.2 & 19.7 & 10.1 & 4.1 & 23.7 & 0.002 & 12.1 & 4.4 & 27.7 & $<0.001$ & 0.001 \\
\hline Saturated fat g/10 MJ & 31.4 & 23.0 & 41.2 & 32.2 & 22.8 & 43.0 & $<0.001$ & 31.7 & 22.3 & 43.2 & 0.182 & 0.682 \\
\hline Fibre, g/10 MJ & 31.3 & 21.1 & 47.7 & 30.1 & 18.3 & 45.9 & $<0.001$ & 27.5 & 14.1 & 39.6 & $<0.001$ & $<0.001$ \\
\hline $\begin{array}{l}\text { Vitamin D from food, } \\
\mu \mathrm{g} / 10 \mathrm{MJ}\end{array}$ & 3.3 & 1.1 & 6.7 & 3.3 & 1.1 & 7.2 & 0.687 & 3.2 & 0.8 & 7.8 & 0.421 & 0.367 \\
\hline Total Vitamin $D^{\dagger}, \mu \mathrm{g} / \mathrm{d}$ & 7.9 & 1.8 & 30.5 & 8.1 & 1.5 & 32.6 & 0.783 & 7.1 & 1.2 & 3.19 & 0.039 & 0.061 \\
\hline Folate food, $\mu \mathrm{g} / 10 \mathrm{MJ}$ & 277 & 190 & 412 & 276 & 178 & 423 & 0.148 & 263 & 162 & 391 & $<0.001$ & 0.011 \\
\hline Total folate ${ }^{\dagger}, \mu \mathrm{g} / \mathrm{d}$ & 445 & 174 & 988 & 426 & 151 & 1010 & 0.023 & 338 & 142 & 926 & $<0.001$ & 0.001 \\
\hline n-3 from supplements ${ }^{\ddagger}, \mathrm{g} /$ day & 0.40 & 0.06 & 2.40 & 0.60 & 0.08 & 2.94 & $<0.001$ & 0.41 & 0.05 & 2.79 & 0.869 & 0.109 \\
\hline Calcium, g/10 MJ & 1.05 & 0.63 & 1.63 & 1.04 & 0.60 & 1.72 & 0.847 & 1.00 & 0.55 & 1.92 & 0.184 & 0.303 \\
\hline Magnesium, mg/10 MJ & 413 & 326 & 512 & 410 & 303 & 530 & 0.124 & 388 & 301 & 495 & 0.001 & $<0 \cdot 001$ \\
\hline
\end{tabular}

Energy \%, percentage of energy contributed by nutrient.

P5, $5^{\text {th }}$ percentile; $P 95,95^{\text {th }}$ percentile.

"Mann-Whitney U test.

${ }^{\dagger}$ Including supplements.

${ }^{\ddagger}$ Intake in supplements users only.

singles living alone group. A previous MoBa study reported that women giving birth to their first baby at an advanced or very advanced age compose a heterogeneous group characterized by either socioeconomic prosperity or vulnerability. Single status was among the socio-demographic factors correlated with giving birth at an advanced age [39]. Although single mothers only represented $1.8 \%$ of the total cohort in this study, single mothers constituted $13 \%$ of all pregnant women in 2013 in the general population and is most likely an increasing group [1].

The main strengths of this study include the large sample size representing women from all regions of Norway, the prospective design, and the comprehensive information about the maternal diet and a wide range of potential confounding factors. However, the low participation rate in MoBa is a concern (40.6\%), with underrepresentation

Table 4 Associations between marital status and pregnancy outcomes in 60,946 women

\begin{tabular}{|c|c|c|c|c|c|c|}
\hline & Total $\mathbf{n}$ & n (\%) & $\begin{array}{l}\text { Unadjusted } \\
\text { OR }(95 \% \mathrm{Cl})\end{array}$ & $\begin{array}{l}\text { Model } 1 * \\
\text { Adjusted OR }(95 \% \mathrm{Cl})\end{array}$ & $\begin{array}{l}\text { Model }^{\dagger} \\
\text { Adjusted OR }(95 \% \mathrm{Cl})\end{array}$ & $\begin{array}{l}\text { Model } 3^{\ddagger} \\
\text { Adjusted OR }(95 \% \mathrm{Cl})\end{array}$ \\
\hline \multicolumn{7}{|c|}{ Small for gestational age baby } \\
\hline Married/cohabiting & 59,845 & $6289(10.5)$ & 1 & 1 & 1 & 1 \\
\hline Singles living alone & 888 & $123(13.9)$ & $1.37(1.13,1.66)$ & $1.36(1.12,1.64)$ & $1.27(1.05,1.55)$ & $1.10(0.90,1.34)$ \\
\hline Singles living with parents & 213 & $22(10.3)$ & $0.98(0.63,1.53)$ & $0.93(0.59,1.45)$ & $0.96(0.61,1.50)$ & $0.82(0.52,1.29)$ \\
\hline \multicolumn{7}{|c|}{ Large for gestational age baby } \\
\hline Married/cohabiting & 59,845 & $5839(9.8)$ & 1 & 1 & 1 & 1 \\
\hline Singles living alone & 888 & $80(9.0)$ & $0.92(0.73,1.15)$ & $0.88(0.70,1.11)$ & $0.87(0.69,1.10)$ & $0.94(0.75,1.20)$ \\
\hline Singles living with parents & 213 & $24(11.3)$ & $1.17(0.77,1.80)$ & $1.20(0.78,1.84)$ & $1.11(0.72,1.71)$ & $1.20(0.78,1.87)$ \\
\hline \multicolumn{7}{|c|}{ Preterm delivery ( $<37$ weeks) } \\
\hline Married/cohabiting & 59,845 & $2966(5.0)$ & 1 & 1 & 1 & 1 \\
\hline Singles living alone & 888 & $59(6.6)$ & $1.36(1.05,1.78)$ & $1.32(1.01,1.72)$ & $1.17(0.89,1.53)$ & $1.15(0.88,1.51)$ \\
\hline Singles living with parents & 213 & $12(5.6)$ & $1.14(0.64,2.05)$ & $1.09(0.61,1.95)$ & $0.91(0.50,1.64)$ & $0.89(0.49,1.61)$ \\
\hline
\end{tabular}

${ }^{*}$ Model 1: adjusted for maternal pre-pregnancy BMI, total energy intake and energy contributed by protein.

${ }^{\dagger}$ Model 2: additional adjusted for maternal education, income, parity, age at delivery and nausea at the time of filling in the FFQ.

${ }^{\ddagger}$ Model 3: additional adjusted for maternal smoking during pregnancy. 
of women aged less than 25 years, smokers, those living alone, those with more than two previous births and those with previous stillbirths [40]. The potential selection bias in MoBa has been evaluated, and despite differences in prevalence estimates, associations between eight exposures and outcomes did not differ between MoBa and a representative sample from the national birth registry [40].

The MoBa FFQ has been thoroughly validated, but the FFQ method has several limitations. Answering a FFQ challenges the respondents with rather complex cognitive skills, such as reporting the average intake of a given food or dish during the time period covered. FFQ's are subject to recall bias, and are not a precise instrument to estimate nutrient intakes on an individual level. Nevertheless, FFQs have proved to be an appropriate method to capture an image of the distribution of the intake of energy, nutrients and foods on a population level $[27,41]$. Although MoBa participants were not representative and have a healthier lifestyle than the general population of pregnant women, few women fulfil the dietary recommendations [20].

Maternal smoking, poor gestational nutrition and low pre-pregnancy weight are the most important modifiable risk factors for foetal growth restriction in developed countries [42]. In our study, all of these factors were more prevalent in the two single groups than in married/cohabiting women (Table 1).

\section{Conclusions}

The current study showed that single mothers had lower dietary quality than women who lived with a partner. This was reflected by higher intake of energy, particularly energy contributed by added sugar, lower intake of dietary fibre and lower intake of energy contributed by protein. Single mothers living alone had higher prevalence of SGA and preterm delivery, but the associations with the adverse pregnancy outcomes were confounded by other variables, particularly smoking and educational attainment. Our results show that the risk is not equally distributed among single women. This study shows that single mothers should be given special attention during antenatal care and counselling.

\begin{abstract}
Abbreviations
BMI: Body mass index; Cl: Confidence interval; FFQ: Food frequency questionnaire; MoBa: The Norwegian Mother and Child Cohort Study; MBRN: Medical birth registry of Norway; SP: Singles living with parents; SA: Singles living alone; M/C: Married/cohabiting; NOK: Norwegian crowns, currency; SGA: Small for gestational age; LGA: Large for gestational age.
\end{abstract}

\section{Competing interests}

The authors declare that they have no competing interests.

\section{Authors' contributions}

All authors planned the study. MH calculated all food and nutrient intakes. JF conducted the statistical analyses and drafted the paper. ALB and MH assisted with statistical analyses. All authors contributed to the interpretation of the results. HMM contributed with writing of the paper and all authors reviewed the paper and approved the final manuscript.

\section{Acknowledgements}

The Norwegian Mother and Child Cohort Study is supported by the Norwegian Ministry of Health and the Ministry of Education and Research, $\mathrm{NIH/NIEHS} \mathrm{(contract} \mathrm{no.} \mathrm{N01-ES-75558),} \mathrm{NIH/NINDS} \mathrm{(grant} \mathrm{no.} 1$ UO1 NS 047537-01 and grant no. 2 UO1 NS 047537-06A1). We are grateful to all the participating families in Norway who take part in this on-going cohort study.

Received: 2 September 2014 Accepted: 18 November 2014

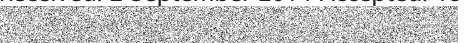

\section{References}

1. SSB: Statistics Norway. Norway: 2014. Available online: https://www.ssb.no/ statistikkbanken [accessed March 2014].

2. Weitoft GR, Hjern A, Haglund B, Rosen M: Mortality, severe morbidity, and injury in children living with single parents in Sweden: a population-based study. Lancet 2003, 361(9354):289-295.

3. Huserbråten K: Enslige har oftere helseproblemer enn andre [Singles have more often health problems than others]. article in Norwegian. Samfunnsspeilet 1996, (1):39-44. Available online www.ssb.no/helse/artiklerog-publikasjoner/_attachment/69991?_ts=137db266a0.

4. Elfhag K, Rasmussen F: Food consumption, eating behaviour and self-esteem among single v. married and cohabiting mothers and their 12-year-old children. Public Health Nutr 2008, 11(9):934-939.

5. Shah PS, Zao J, Ali S: Maternal marital status and birth outcomes: a systematic review and meta-analyses. Matern Child Health J 2011, 15(7):1097-1109.

6. Langley-Evans SC: Nutrition in early life and the programming of adult disease: a review. J Hum Nutr Diet 2014, doi:10.1111/jhn.12212. [Epub ahead of print].

7. Vanhees K, Vonhogen IG, van Schooten FJ, Godschalk RW: You are what you eat, and so are your children: the impact of micronutrients on the epigenetic programming of offspring. Cell Mol Life Sci 2014, 71(2):271-285.

8. Godfrey KM, Barker DJ: Fetal programming and adult health. Public Health Nutr 2001, 4(2B):611-624

9. Shapira N: Prenatal nutrition: a critical window of opportunity for mother and child. Womens Health (Lond Engl) 2008, 4(6):639-656.

10. Moore VM, Davies MJ: Diet during pregnancy, neonatal outcomes and later health. Reprod Fertil Dev 2005, 17(3):341-348.

11. Takaya J, Kaneko K: Small for gestational age and magnesium in cord blood platelets: intrauterine magnesium deficiency may induce metabolic syndrome in later life. J Pregnancy 2011, 2011:270474.

12. Rayman MP, Wijnen $H$, Vader H, Kooistra L, Pop V: Maternal selenium status during early gestation and risk for preterm birth. CMAJ 2011, 183(5):549-555.

13. Kind KL, Moore VM, Davies MJ: Diet around conception and during pregnancy-effects on fetal and neonatal outcomes. Reprod Biomed Online 2006, 12(5):532-541.

14. Brantsaeter AL, Birgisdottir BE, Meltzer HM, Kvalem HE, Alexander J, Magnus P, Haugen M: Maternal seafood consumption and infant birth weight, length and head circumference in the Norwegian Mother and Child Cohort Study. Br J Nutr 2012, 107(3):436-444.

15. Hillesund ER, Bere E, Haugen M, Overby NC: Development of a new nordic diet score and its association with gestational weight gain and fetal growth - a study performed in the Norwegian Mother and Child Cohort Study (MoBa). Public Health Nutr 2014, 17(9):1909-1918.

16. Olsen SF, Halldorsson TI, Willett WC, Knudsen VK, Gillman MW, Mikkelsen TB, Olsen J: Milk consumption during pregnancy is associated with increased infant size at birth: prospective cohort study. Am J Clin Nutr 2007, 86(4):1104-1110.

17. Englund-Ögge L, Brantsaeter AL, Sengpiel V, Haugen M, Birgisdottir BE, Myhre R, Meltzer HM, Jacobsson B: Maternal dietary patterns and preterm delivery: results from large prospective cohort study. BMJ 2014, 348:g1446.

18. Blumfield ML, Hure AJ, Macdonald-Wicks L, Smith R, Collins CE: A systematic review and meta-analysis of micronutrient intakes during pregnancy in developed countries. Nutr Rev 2013, 71(2):118-132.

19. Blumfield ML, Hure AJ, Macdonald-Wicks L, Smith R, Collins CE: Systematic review and meta-analysis of energy and macronutrient intakes during pregnancy in developed countries. Nutr Rev 2012, 70(6):322-336.

20. von Ruesten A, Brantsaeter AL, Haugen M, Meltzer HM, Mehlig K, Winkvist A Lissner L: Adherence of pregnant women to Nordic dietary guidelines in relation to postpartum weight retention: results from the Norwegian Mother and Child Cohort Study. BMC Public Health 2014, 14(1):75. 
21. Northstone $K$, Emmett P, Rogers I: Dietary patterns in pregnancy and associations with socio-demographic and lifestyle factors. Eur J Clin Nutr 2008, 62(4):471-479.

22. Henriksen RE, Torsheim T, Thuen F: Loneliness, social integration and consumption of sugar-containing beverages: testing the social baseline theory. PLoS One 2014, 9(8):e104421.

23. Magnus P, Irgens LM, Haug K, Nystad W, Skjaerven R, Stoltenberg C: Cohort profile: the Norwegian Mother and Child Cohort Study (MoBa). Int $J$ Epidemiol 2006, 35(5):1146-1150.

24. Irgens $L M$ : The Medical Birth Registry of Norway. epidemiological research and surveillance throughout 30 years. Acta Obstet Gynecol Scand 2000, 79(6):435-439.

25. Meltzer HM, Brantsaeter AL, Ydersbond TA, Alexander J, Haugen M: Methodological challenges when monitoring the diet of pregnant women in a large study: experiences from the Norwegian Mother and Child Cohort Study (MoBa). Matern Child Nutr 2008, 4(1):14-27.

26. Lauritsen J: FoodCalc. http://www.ibt.ku.dk/jesper/foodcalc (accessed February 2005).

27. Brantsaeter AL, Haugen M, Alexander J, Meltzer HM: Validity of a new food frequency questionnaire for pregnant women in the Norwegian Mother and Child Cohort Study (MoBa). Matern Child Nutr 2008, 4(1):28-43.

28. Brantsaeter AL, Haugen M, Julshamn K, Alexander J, Meltzer HM: Evaluation of urinary iodine excretion as a biomarker for intake of milk and dairy products in pregnant women in the Norwegian Mother and Child Cohort Study (MoBa). Eur J Clin Nutr 2009, 63(3):347-354.

29. Brantsaeter AL. Haugen M, Rasmussen SE, Alexander J, Samuelsen SO, Meltzer HM: Urine flavonoids and plasma carotenoids in the validation of fruit, vegetable and tea intake during pregnancy in the Norwegian Mother and Child Cohort Study (MoBa). Public Health Nutr 2007, 10(8):838-847.

30. American Psychiatric Association: Diagnostic and statistical manual of mental disorders: DSM-IV. Washington, DC: American Psychiatric Association; 1994.

31. Moran VH: A systematic review of dietary assessments of pregnant adolescents in industrialised countries. Br J Nutr 2007, 97(3):411-425.

32. Baker PN: Possible dietary measures in the prevention of pre-eclampsia and eclampsia. Baillieres Clin Obstet Gynaecol 1995, 9(3):497-507.

33. Lawlor DA, Shaw M: Too much too young? teenage pregnancy is not a public health problem. Int J Epidemiol 2002, 31(3):552-554

34. Nilsen SM, Krokstad S, Holmen TL, Westin S: Adolescents' health-related dietary patterns by parental socio-economic position, the Nord-Trondelag Health Study (HUNT). Eur J Public Health 2010, 20(3):299-305.

35. Lurie S, Zalmanovitch A, Golan A, Sadan O: The effect of marital status on pregnancy outcome in Israel: a retrospective case-control study. J Obstet Gynaecol Res 2010, 36(6):1161-1164.

36. Petersen CB, Mortensen LH, Morgen CS, Madsen M, Schnor O, Arntzen A, Gissler M, Cnattingius S, Andersen AM: Socio-economic inequality in preterm birth: a comparative study of the Nordic countries from 1981 to 2000. Paediatr Perinat Epidemiol 2009, 23(1):66-75.

37. Lund KE, Lund M: Smoking and social inequality in Norway 1998-2000. Tidsskr Nor Laegeforen 2005, 125(5):560-563.

38. Brandhagen M, Lissner L, Brantsaeter AL, Meltzer HM, Haggkvist AP, Haugen M, Winkvist A: Breast-feeding in relation to weight retention up to 36 months postpartum in the Norwegian Mother and Child Cohort Study: modification by socio-economic status? Public Health Nutr 2014, 17(7):1514-1523.

39. Nilsen AB, Waldenstrom U, Hjelmstedt A, Rasmussen $S$, Schytt E: Characteristics of women who are pregnant with their first baby at an advanced age. Acta Obstet Gynecol Scand 2012, 91(3):353-362x.

40. Nilsen RM, Vollset SE, Gjessing HK, Skjaerven R, Melve KK, Schreuder P, Alsaker ER, Haug K, Daltveit AK, Magnus P: Self-selection and bias in a large prospective pregnancy cohort in Norway. Paediatr Perinat Epidemiol 2009, 23(6):597-608.

41. Willett WC: Food Frequency Methods. In Nutrition Epidemiology. 2nd edn. Edited by Willett WC. New York: Oxford University Press; 1998:74-100.

42. Kramer MS: Determinants of low birth weight: methodological assessment and meta-analysis. Bull World Health Organ 1987, 65(5):663-737.

\section{doi:10.1186/s12884-014-0396-9}

Cite this article as: Farbu et al:: Impact of singlehood during pregnancy on dietary intake and birth outcomes- a study in the Norwegian Mother and Child Cohort Study. BMC Pregnancy and Childbirth 2014 14:396.

\section{Submit your next manuscript to BioMed Central and take full advantage of:}

- Convenient online submission

- Thorough peer review

- No space constraints or color figure charges

- Immediate publication on acceptance

- Inclusion in PubMed, CAS, Scopus and Google Scholar

- Research which is freely available for redistribution 